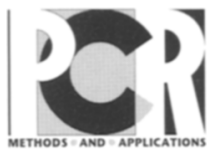

\title{
Accurate and Absolute Quantitative Measurement of Gene Expression by Single-tube RT-PCR and HPLC
}

\author{
Amanda Hayward-Lester, ${ }^{1}$ Peter J. Oefner, ${ }^{2,4}$ Sandra Sabatini, $^{3}$ and Peter A. Doris ${ }^{1}$
}

\author{
${ }^{1}$ Department of Cell Biology and Biochemistry and ${ }^{2}$ Departments of Physiology and Internal Medicine, Texas Tech University \\ Health Sciences Center, Lubbock, Texas 79430; ${ }^{3}$ Department of Biochemistry, Stanford University, \\ Stanford, California 94305 USA
}

We report a method that allows accurate, absolute quantification of gene expression in a single reverse transcriptase (RT)-PCR reaction. This method makes use of novel high-performance liquid chromatography (HPLC) technology to resolve and quantify the products of competitive, mutant RNA PCRs. The HPLC technique allows rapid, high resolution of reaction products. On-line UV detection eliminates the need for radiolabel or other tracers. The HPLC technique also demonstrates that these competition reactions readily generate heteroduplex products. The ability of HPLC to resolve and quantify heteroduplex products is fundamental to the accuracy of the technique. Accurate measurements of gene expression have been obtained over four orders of magnitude and experiments employing predetermined quantities of specific native RNA input have demonstrated the ability of the system to provide absolute estimates of gene expression. Large size differences between native and mutant RNA inputs affected reverse transcriptase ( $R T$ ) efficiency, but not PCR amplification efficiency. However, the magnitude of the RT efficiency effect can be estimated, is reproducible, and can therefore be adjusted by a calculated correction factor. The RT efficiency difference can been eliminated by re- duction in the magnitude of the sequence difference between native and mutant RNA so that no correction factor is required. The application of the technique to quantification of expression of the alpha 1 subunit of sodium, potassium-ATP ase in microdissected nephron segments is demonstrated.

A of specific nucleic acid sequences are reof specific nucleic acid sequences are required in a rapidly increasing number of circumstances. These include determination of viral burden in infectious disease to aid diagnosis and therapy, examination of tumor suppressor gene expression as in situ neoplastic tissue progresses to invasion, and drug resistance development in chemotherapy. ${ }^{(1-4)}$ Furthermore, quantitative gene expression measurements provide information about the likely type and level of protein present, as well as its response to perturbation, in circumstances where tissue amounts or organ microstructure are too small to provide reliable direct information about the protein itself. At present, the prevailing strategy for quantification is competitive RT-PCR. ${ }^{(5,6)}$

Competitive approaches provide the prospect of both accurate and absolute quantification. However, the exponential nature of the amplification reaction imposes two primary constraints that must be met for measurements to be reliable. First, the PCR amplification efficiency of native and competitor inputs must be identical. Second, the decline in amplification efficiency that occurs as reactions proceed to plateau (a necessary constraint for the quantification of low abundance signals) must affect both native and competitor inputs identically. A mathematical model of competitive PCR reactions has been devised. ${ }^{(7)}$ Although incorporating only the evident parameters, this model indicates the computational consequences if these constraints are not met. It is widely noted that competitive RT-PCR reactions used to quantitate nucleic acids generally fail to meet these fundamental predictions implicit in exponential amplification with identical efficiency.

Recent advances in reversed-phase high-performance liquid chromatography (HPLC) technology now permit the rapid analysis and quantification of double-stranded DNA. ${ }^{(8,9)}$ This technology offers significant advantages to the analysis of competitive reactions that can contribute to increased accuracy. We have employed HPLC in conjunction with competitive RT-PCR: (1) to examine transcription and amplification efficiency in competitive RT-PCR reactions; (2) to determine the accuracy of quantitation using predetermined RNA and DNA inputs; (3) to examine the precision of the measurement system; (4) to 
examine the ability of quantitative accuracy to be preserved over a wide range of input RNA; and (5) to determine whether accurate, precise measurements can be obtained in single-tube assays, which avoid the labor, time, and expense of multiple titrations.

\section{MATERIALS AND METHODS}

RNA was transcribed from the T7 RNA polymerase promoter of a pGem $4 \mathrm{Z}$ construct containing a 396-bp rat $\alpha 1$, sodium, potassium-ATPase (A1NKA) sequence. Two mutant RNAs (541-bp insertion mutant and 382-bp deletion mutant) were transcribed from similar constructs containing the same 396-bp native sequence interrupted by a 145-bp insertion or a 14-bp deletion, respectively. After determination of the RNA yield by UV absorbance, the transcribed RNA was diluted in a solution of yeast total RNA to reduce nonspecific binding to plastic surfaces and to minimize degradation by RNase. RNA dilutions were made in the same yeast RNA buffer. Each RNA mixture was reverse transcribed at $42^{\circ} \mathrm{C}$ for $25 \mathrm{~min}$ in a Peltier effect thermal cycler (MJ Research, Watertown, MA). Reaction volumes $(10 \mu \mathrm{l}$ with a $20-\mu 1$ wax overlay) comprised Per-
kin-Elmer reagents, including Moloney murine leukemia virus (MMLV) RT and random hexameric primers. After heating the reactions to $99^{\circ} \mathrm{C}$ and cooling to $5^{\circ} \mathrm{C}, 40 \mu \mathrm{l}$ of PCR reaction mastermix containing AmpliTaq DNA polymerase $(1.25 \mathrm{U} / 40 \mu \mathrm{l})$, and $0.3 \mu \mathrm{M}$ each $\alpha 1$ primer was added to each tube. Standard cycling parameters were as follows: 2 min at $95^{\circ} \mathrm{C}$, followed by 36 cycles of 50 sec at $94^{\circ} \mathrm{C}, 60 \mathrm{sec}$ at $56^{\circ} \mathrm{C}$, and $70 \mathrm{sec}$ at $72^{\circ} \mathrm{C}$, with a final extension of $5 \mathrm{~min}$ at $72^{\circ} \mathrm{C}$. Samples were cooled rapidly and held at $0^{\circ} \mathrm{C}$ until analysis.

Primers were designed to avoid selfcomplementarity and to span an intron, so as to distinguish cDNA amplification from possible contaminating genomic DNA amplification. The sequence of the forward primer was 5'-CCCTAGTTCCCGCCTCTC; the reverse primer was 5'TGGTCGTCCATAGACACTTCC. Reaction products were subjected to agarose gel electrophoresis and ion-pair reversed-phase HPLC [DNASep column, alkylated polystyrene-divinylbenzene (PS-DVB) packing, Sarasep Inc, Santa Clara, CA]. ${ }^{(9,10)}$ HPLC was performed without further treatment of reaction products. The amount of product was determined by on-line UV absorbance detection, and no labeling of reaction products was required.

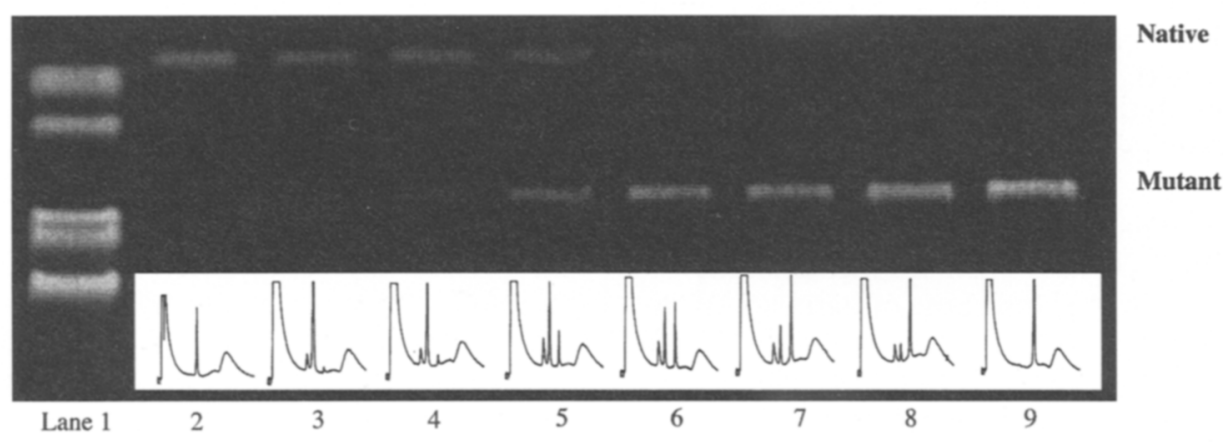

FIGURE 1 Analysis by HPLC and agarose gel electrophoresis of products from a single RT-PCR titration series. Aliquots from RT-PCR $(15 \mu \mathrm{l})$ were run on a $5 \%$ Metaphor gel (FMC, Rockland, ME) at $50 \mathrm{~V}$ for $2.5 \mathrm{hr}$ in $1 \times$ TPE buffer. The gel was poststained with ethidium bromide, photographed under UV illumination, and analyzed by densitometry using NIH Image 1.55. For HPLC, aliquots of the same reaction products $(6 \mu \mathrm{l})$ were injected sequentially onto the PS-DVB HPLC column at $\sim 6.5-\mathrm{min}$ intervals. The elution system was a gradient of acetonitrile in $0.1 \mathrm{M}$ TEAA ( $\mathrm{pH} 7.0$ ), $1 \mathrm{ml} / \mathrm{min}$. UV detection was at $254 \mathrm{~nm}$, and the UV absorbance signal was analyzed by an online integrator. No processing of PCR products was required prior to injection. Each reaction in the titration contained $25 \mathrm{ng}$ of rat brain total RNA input with varying mutant input. (Lane 1) A pUC18 HaelII ladder; (lane 2) RT-PCR products of native RNA only; (lanes 3-8) competitive reaction products in which native RNA was subject to RT-PCR with $0.25,0.5,1,2$, 4 , and 8 pg of mutant RNA, respectively; (lane 9) RT-PCR products of 4 pg of mutant RNA only. Only two bands are evident from the competition reactions on gel electrophoresis, whereas the HPLC chromatograms reveal the presence of a heteroduplex product in reactions in which both inputs are present.

\section{RESULTS}

\section{Analysis of Reaction Products: HPLC vs. Gel Electrophoresis}

Figure 1 shows the analysis of reaction products by agarose gel electrophoresis and HPLC from a competitive titration in which six different levels of the 541bp insertion mutant RNA were subject to RT-PCR in the presence of constant amounts of native rat brain RNA. Agarose gel electrophoresis revealed two principal reaction products visualized by ethidium bromide fluorescence, the ratios of which changed to reflect the changing proportion of reaction input RNA. Subsequent regression analysis revealed that the densitometric analysis of the gel provided an estimate of molecule number approximately one-third of that estimated by the HPLC analysis. This indicates that most of the heteroduplex product comigrates with the mutant product during agarose electrophoresis, overestimating the amount of mutant product formed and causing erroneous quantification. It is an important property of this HPLC system to reliably resolve heteroduplex from homoduplex products. For accurate quantification, the peak area of heteroduplex products is divided in proportion to the UV absorbance contributed by each heteroduplex component (native strand, 39\%; mutant strand, $61 \%$ ), and each component is added back to its appropriate homoduplex peak prior to calculation of native/mutant product ratios.

\section{Demonstration of Heteroduplex Formation}

HPLC of the reaction products revealed the existence of a third product peak that was most prominent when individual reactions produced significant amounts of both native and mutant products, rather than at the extremes of the titration when one product predominated. Further examination of the additional peak revealed that it was a heteroduplex peak resulting from the annealing of native and mutant reaction products. Separate RT-PCR reactions were performed containing either native or mutant input RNA. When products resulting from individual native and mutant reactions were mixed, and the mixture analyzed by HPLC, only two peaks resulted. When an aliquot of this 


\section{HAYWARD-LESIER ET AL.}

mixture was heated to $95^{\circ} \mathrm{C}$, cooled, and analyzed, the third peak (heteroduplex) became evident, which coeluted with the third peak produced in competition reactions. The relative size of this peak is influenced by the rate of cooling and may be selectively removed by treatment with S1 nuclease. The heteroduplex product elutes before the native product because retention time is determined by the interaction of ion-pairing reagents with paired bases. Heteroduplex product contains fewer paired bases than native homoduplex because of incomplete complementarity.

\section{Quantitative Data Analysis}

The quantification method requires calculation of the ratio of reaction products. ${ }^{(11)}$ The formation of heteroduplex subtracts equally from the numerator and denominator of this ratio only when the reaction products are fortuitously present in exactly equal amounts. Therefore, it was essential that the portion of the heteroduplex peak attributable to the native and mutant reaction products be redistributed to their product of origin. A spreadsheet was developed that reallocated the absorbance produced relative to heteroduplex according to the size of each component of the heteroduplex. The spreadsheet was used further to perform regression analysis and plot the logarithm of the mutant competitor input against the log of the corrected ratios of reaction products. Such a plot should generate a straight line with a slope of unity if the PCR amplification efficiencies of the native and mutant inputs are identical throughout the reaction. The mathematical basis of these requirements have been discussed elsewhere. ${ }^{(7)}$ However, published methods have paid little attention to both these requirements and when such analysis has been present, these requirements are generally not approached. Robust titrations that consistently conform to slope and linearity properties constraining competitive reactions were obtained (mean slope and $\mathrm{R}^{2}$ for these reactions was $1.01 \pm 0.01$ and $0.99 \pm 0.005$, respectively, mean \pm S.E.M., $n=18$.)

\section{Mutant Selection}

Selection of a mutant for competitive RT-PCR is a critical component of the strategy. Our 541-bp insertion mutant produced a PCR product that shared only $63 \%$ homology with the native product so as to minimize the likelihood of heteroduplex formation. However, this readily occurred in reactions that proceeded into the plateau phase. The production of mutants that differ by the presence of a small base change to provide a specific restriction cleavage site are even more likely to generate such heteroduplexes. In this case, error can be expected owing to the inability of the heteroduplex to be cleaved and to the extra postreaction handling necessary in the restriction digestion step.

Evidence that the substantial size mutation was not responsible for altered PCR amplification efficiency was obtained by diluting native input RNA over four orders of magnitude and performing competitive titrations at each input level. The results are shown in Figure 2 and revealed the preservation of slope and linearity attributes of the regression analysis and reproducible quantification at each of the levels of input.

\section{Validation of Absolute Quantification and Determination of Accuracy}

Our goal was to develop a method of quantification that was absolute (correctly able to measure the actual number of input native mRNA molecules). ${ }^{(12)}$ To determine whether HPLC analysis provided these conditions we performed quantitative titrations using known amounts of native RNA transcribed from the plasmid construct in competitions with known amounts of the 541-bp insertion mutant RNA. The results of these reactions indicated that there was a consistent difference in the estimated amount of native input RNA compared with the known amount. This difference was overestimated by $3.79 \pm 0.20$-fold (all values are mean \pm S.E.M., $n=18$ ). The source of this consistent difference was RT efficiency. When known amounts of native and insertion mutant DNA were coamplified, the titrations accurately estimated the known amount $\left(15.5 \times 10^{3}\right.$ molecules $)$ of input DNA $\left(-16.8 \times 10^{3} \pm 1.4 \times 10^{3}\right.$ molecules $)$, and the slope and linearity properties were preserved as before (mean slope and $\mathrm{R}^{2}$ were $1.02 \pm 0.03$ and $0.99 \pm 0.003$, respectively). A constant RT efficiency dif- ference allows absolute quantification of gene expression as long as this constant is determined.

The ease with which heteroduplexes can form and the critical need to analyze them to preserve the mathematical analysis indicates that mutants should be designed so that heteroduplexes can be identified easily. Within the constraints of HPLC resolution, that is, design of a mutant sufficiently different in size so that its homoduplex reaction product can be adequately separated from the native homoduplex product and provision of sufficient nonhomology so that the resulting heteroduplexes are also adequately resolved from both homoduplex products. The PS-DVB column permits size differences as small as 10 bases to be resolved. A competitive mutant was generated that differed by only $14 \mathrm{bp}$ (internal deletion) from the native amplicon. When this mutant was used in competitive RT-PCR reactions with known amounts of transcribed native RNA the difference in the estimated amount of native input RNA compared with the known amount was $0.95 \pm 0.06$-fold (all values are mean \pm S.E.M., $n=12$ ). Slope and $\mathrm{R}^{2}$ values obtained in these titrations were $0.98 \pm 0.032$ and $0.99 \pm 0.005$, respectively. Thus, by using a mutant of increased homology, absolute quantification is possible without a correction factor.

\section{Determination of Precision}

In addition to providing accurate measurements, we also examined the precision of measurements made with this quantification system. Precision was determined by analyzing the same sample of RNA repeatedly by competitive RT-PCR and HPLC and determining the variance in the results obtained. Using RNA from a tissue in which A1NKA gene expression is relatively abundant (brain), we observed a coefficient of variation $(\mathrm{CV})$ of $8.3 \%$ in samples $(n=5)$ in which gene expression was $8.82 \times 10^{7} \pm 0.33 \times 10^{7}$ molecules of A1NKA per microgram of total RNA. Precision was also estimated for low copy number sources by performing the same analysis on RNA from microdissected nephron segments. We observed a CV of $17.8 \%$ in these samples $(n=6)$, in which the level of expression was $16.8 \times 10^{2} \pm 1.22 \times 10^{2}$ molecules/0.025 $\mathrm{mm}$ of nephron sample. 


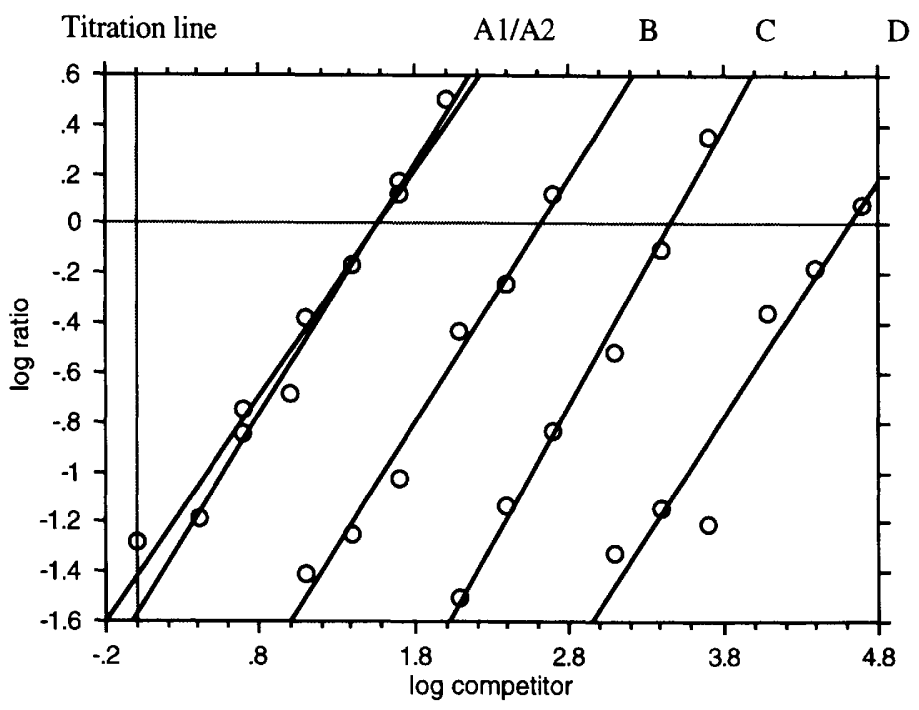

FIGURE 2 Regression lines generated from RT-PCR titrations to quantify A1NKA molecules at four known input levels. Each titration comprised a fixed initial number of native molecules per tube: $(A) 1.13 \times 10^{4} ;(B) 1.13 \times 10^{5}$; (C) $1.13 \times 10^{6} ;(D) 1.13 \times 10^{7}$ with appropriate varying competitive mutant RNA input. For each regression, $10-\mu \mathrm{l}$ aliquots of reaction products were analyzed by HPLC. Raw area values for the mutant peak were adjusted for the relative base length difference between the native and mutant products. The heteroduplex peak area was reapportioned to each homoduplex peak as described previously. The logarithm of the ratio of the two products was then plotted against the logarithm of the initial amount of mutant RNA in each tube. The initial amount of A1NKA native RNA can be estimated by extrapolation from the point on the line at which the $\log$ product ratio $=0$. The intersection of the titration lines with $\log$ ratio $=0$ shifts appropriately with the change in input level. The slopes of the lines were shown by analysis of covariance to be indistinguishable from one another. In addition, the slope and $\mathrm{R}^{2}$ values did not differ significantly from unity, demonstrating the feasibility of quantification over at least four orders of magnitude.

\section{Quantification in Single Tube Reactions}

Quantification of gene expression by titration is essential in demonstrating that the quantitation system is conforming to slope and linearity ideals discussed above. However, once demonstrated for a system, there is no theoretical reason why a single analysis (one competition between a single, known dose of competitor and native RNA) should not be used for quantification. This fact derives from the principle that if PCR amplification efficiency is identical, then the ratio of products at the end of the reaction should always reflect the ratio at the beginning, and using a detection system with sufficient linear range, only one reaction is required to estimate this ratio. We tested this supposition by comparing the result of quantification by titration with the result obtained by single-tube assays using the same sample. Furthermore, we compared the precision of single-tube quantification with that of titration. Comparison was made at both high and low initial signal abundance by using brain and nephron segment RNAs. Re-

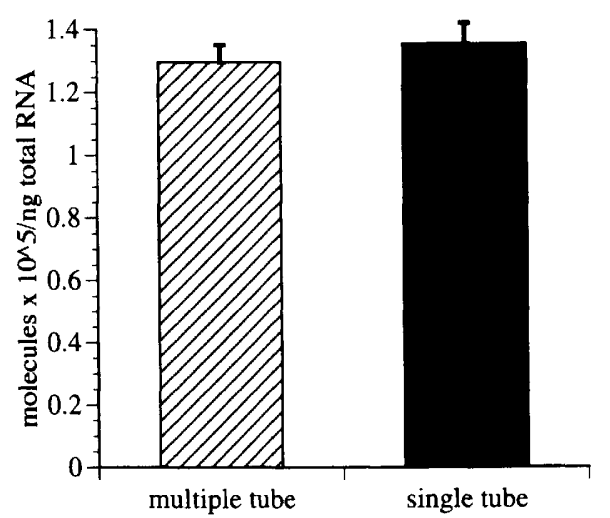

brain of products of a single-tube reaction. sults were essentially identical in both systems (Fig. 3).

\section{DISCUSSION}

This work demonstrates the absolute and accurate measurement of gene expression. It confirms the utility of HPLC as a rapid and accurate means of analyzing reaction products and the importance of detecting and quantifying heteroduplexes formed in competition reactions to the accuracy of the system. Using this system, all mathematical requirements of competitive reactions can be attained consistently. Accuracy and precision of measurements is excellent and once performance parameters of a specific quantification system have been established, extensive titration analysis can be replaced with quantification of single reactions.

The ability to detect heteroduplices is a primary advantage of this quantitation system. We have demonstrated that heteroduplex formation occurs readily when competitive PCR reactions proceed beyond the linear range (Fig. 3). At the beginning of every cycle of competitive PCR all of the products are denatured. Any molecules that subsequently fail to bind a primer and undergo extension will either reanneal to their complement (forming a homoduplex molecule) or to their partially homologous nephron

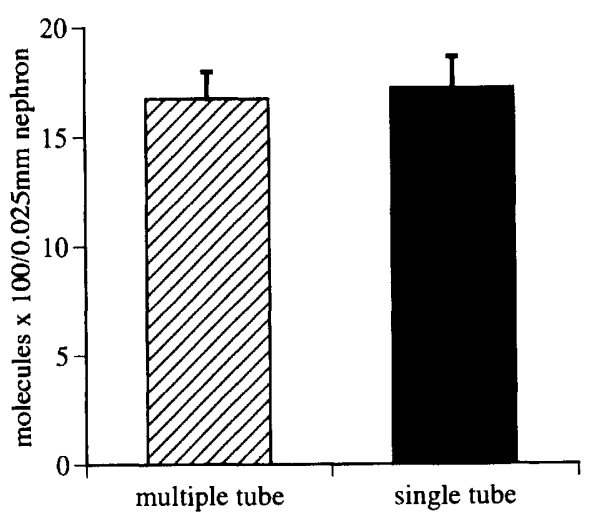

FIGURE 3 Estimation of precision of measurement of A1NKA RNA comparing multiple-tube titration with single-tube quantification for high-abundance (brain) and low-abundance (nephron) samples. For each tissue, multiple measurements were made from one RNA sample, analysis of reaction products was by HPLC, and the results are shown as mean \pm S.E.M. These data confirm that once the system is demonstrated to obey theoretical requirements for quantification, titration is not required and precise estimates of gene expression can be obtained from the analysis 
mutant complement (resulting in a heteroduplex). This constitutes the plateau phase of the reaction, and heteroduplex formation may be viewed as an indicator of the reaction phase. Detection by HPLC therefore provides a convenient means of assessing whether a particular reaction has proceeded beyond the linear range. A second important advantage we have demonstrated is that heteroduplex products may be easily quantified by HPLC and their resulting peak areas reallocated to the respective homoduplex values. Therefore, HPLC permits quantitative reactions to be performed that are not limited to the linear range, obviating the necessity for sample-dependent cycle number optimization.

Failure to detect heteroduplex molecules formed during competitive PCR may result in inaccurate quantitation. This is especially pertinent when internal competitors are constructed that differ only by the presence or absence of a restriction enzyme site. Under these circumstances, heteroduplex molecules will fail to be recognized and cleaved by the enzyme resulting in their erroneous inclusion with the nondigestible homoduplex products during analysis. This is well illustrated in Figure 4 . The problem may be circumvented by ensuring the reaction is limited to the linear range. ${ }^{(13,14)}$ This may be facilitated by the increased sensitivity afforded by the use of fluorescent primers. It may also be possible, if ideal conditions exist, to compute the initial ratio of competitor and native templates mathematically if the amount of digestible products is quantified accurately. ${ }^{(15)}$ However, in either case, restriction enzyme digestion adds a further processing step, increasing the cost and time involved in the analysis and introducing the possibility of new sources of imprecision. Using our approaches, postreaction handling is minimized and quantification beyond the linear range of PCR reactions is feasible and accurate.

Several other methods used to achieve
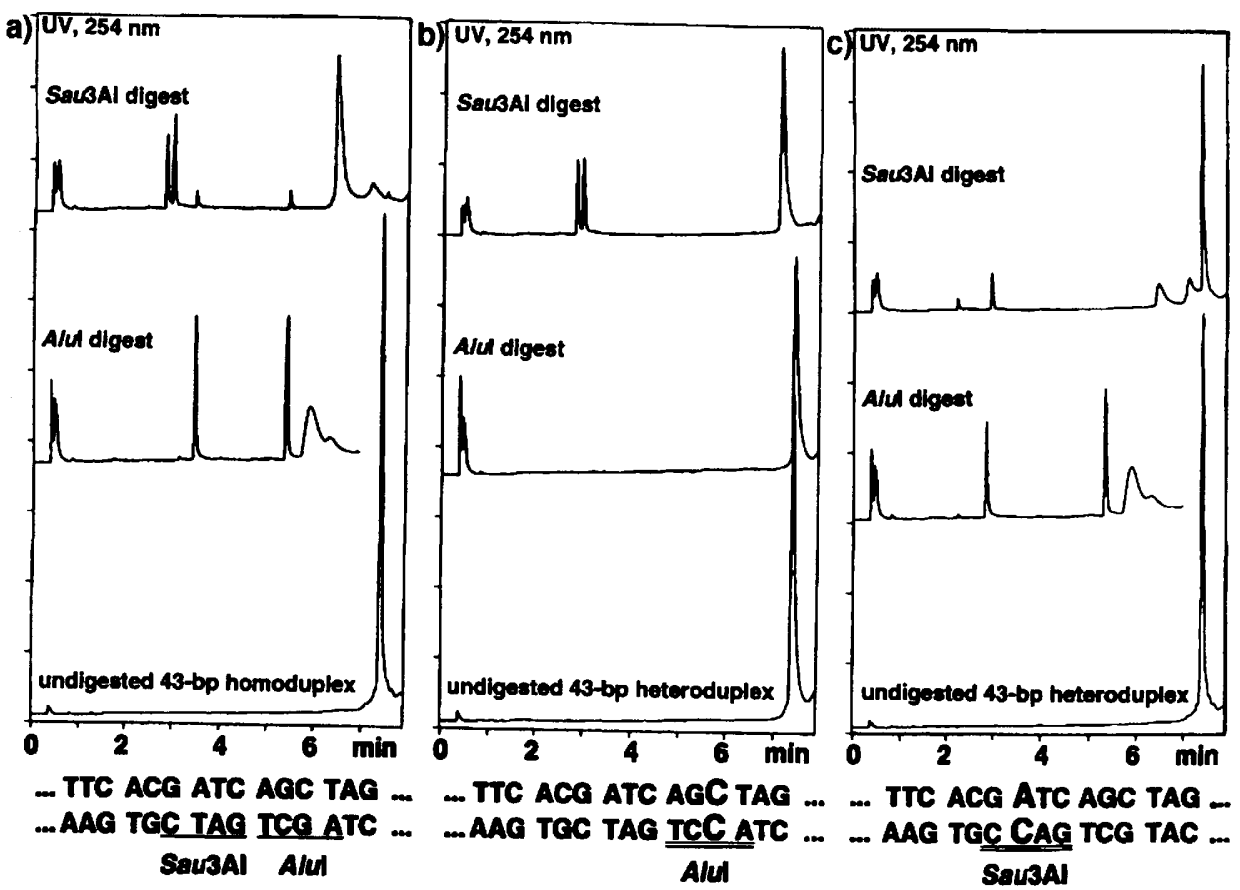

FIGURE 4 Effect of single-point differences in restriction enzyme recognition sequence on digestibility. Heteroduplexes were formed by annealing complementary 43-bp oligonucleotides that were identical except for point mutations affecting either a Sau3AI or an AluI restriction site. (a) The elution profile of undigested homoduplex and the digested fragments created when the homoduplex contained intact Sau3AI and AluI restriction sites (the first peak eluting at the solvent front is unretained material such as protein; the doublet peak in the smaller Sau3AI represents denaturation of the complementary 8 - and 12-base strands cleaved by this enzyme). (b) The effect on digestibility of a point mutation in one of the complementary oligonucleotides that affects the AluI site. (c) The effect on a single-base-pair substitution in one of the complementary strands that affects the Sau3AI site. accurate and reliable quantification of specific RNA and DNA inputs have been developed and it is worthwhile to contrast the attributes of these methods with our HPLC-based technique. Automated sequencers have been used in combination with fluorescent primers to detect and quantify products from competitive PCR. ${ }^{(16)}$ Accurate estimates should be achievable in this system so long as denaturing electrophoresis is used to assure the separation of heteroduplexes. However, this equipment is less readily available and more expensive than HPLC.

An approach using minisequencing of streptavidin-immobilized, biotinylated competitive PCR products has been developed by Ilkonen and colleagues. ${ }^{(17)}$ This method offers the possibility of running a large number of samples at once. However, post-PCR sample processing is complex, involving extensive liquid handling, radioisotopes, and liquid scintillation counting. This provides many opportunities to introduce errors into the system. Another approach using biotinylated reagents links PCR to an enzyme immunoassay. (18) Biotinylated RNA probes are hybridized to the PCR products, and the RNA-DNA hybrids are immobilized with anti-biotin antibodies. The immobilized materials are then bound by DNA-RNA Fab antibody coupled to $\beta$-galactosidase. After washing and the addition of substrate and substrate hydrolysis, fluorescence of the reaction product is determined. Again, post-PCR sample processing is extensive and the wide number of steps and reagents employed may adversely influence reliability and precision.

Nucleic acid side chain branching assays (NASBAs) have been developed for the quantitation of specific viral nucleic acid sequences. ${ }^{(19)}$ By coupling this assay with electrochemiluminescent probe technology, a one-tube assay system has been reported for HIV-1. The precision and accuracy of this system have been thoroughly investigated and the use of a well-defined HIV-1 reference (quantitated by electron microscopy) is certainly an important feature of this assay system. The assay system offers the possibility of analyzing a large number of samples in parallel with opportunities for automation. This approach has revealed two primary weaknesses. First, the system is suitable only for RNA inputs, whereas our competitive PCR/ 
HPLC system has been useful for quantifying either RNA or DNA. Perhaps of greater concern is that precision of this assay is low. Althugh we obtained CVs of variation in our estimates $<10 \%$, the NASBA HIV-1 assay indicates much less precision with CVs of variation approaching $70 \%$. Arguably, the ability to make measurements at the level of precision we have obtained is not always vital in clinical virology; however, high CVs may impede the ability to make reliable clinical assessments and treatment decisions in all conditions.

In summary, the important advantages of HPLC include the ability to resolve amplicons (competitor and native) differing by only $10 \mathrm{bp}$ or more, the ability to resolve heteroduplexes, and the opportunity to automate processing of samples with minimal post-PCR sample handling. Competitor RNA can be synthesized that provides essentially identical RT efficiency and thereby simplifies the calculation of unknowns. Using our approaches, quantification beyond the linear range of PCR reactions is feasible, precise, and accurate, and reliable measurements of gene expression can be obtained easily in samples as small as microdissected nephron segments.

\section{ACKNOWLEDGMENTS}

This work was supported in part by $\mathrm{Na}$ tional Institute of Heath grants DDK45538 (PAD), IPO1-HG00205 (PJO), and DDK36119 (SS). We are grateful to Dr. Jerry Lingrel (University of Cincinnati, $\mathrm{OH}$ ) and Dr. Kevin Lynch (University of Virginia, Charlottesville) for $\mathrm{cD}$ NAs used in this study.

The publication costs of this article were defrayed in part by payment of page charges. This article must therefore be hereby marked "advertisement" in accordance with 18 USC section 1734 solely to indicate this fact.

\section{REFERENCES}

1. Clementi, M., S. Menzo, P. Bagnarelli, A. Manzin, A. Valenza, and P.E. Varaldo. 1993. Quantitative PCR and RT-PCR in virology. PCR Methods Applic. 2: 191-196.

2. Noonan, K.E., C. Beck, T.A. Holzmayer, J.E. Chin, J.S. Wunder, I.L. Andrulis, A.F. Gazdar, C.L. Willman, B. Griffith, D.D. Von Hoff, and I.B. Roninson. 1990. Quantitative analysis of MDR1 gene expression in human tumors by polymerase chain reaction. Proc. Natl. Acad. Sci.
87: 7160-7164.

3. Piatak, M., K.-C. Luk, B. Williams, and J.D. Lifson. 1993. Quantitative competitive polymerase chain reaction for accurate quantification of HIV DNA and RNA species. BioTechniques 14: 70-80.

4. Thompson, M.E., R.A. Jensen, P.S. Obermiller, D.L. Page, and T.J. Holt. 1995. Decreased expression of BRCA1 accelerates growth and is often present during sporadic breast cancer progression. Nature Genet. 9: 444-450.

5. Chelly, J. and A. Kahn. 1994. RT-PCR and mRNA quantification. In The polymerase chain reaction (ed. K.B. Mullis, F. Ferré, and R.A. Gibbs), pp. 97-109. Birkhauser, Boston, MA.

6. Ferré, F., A. Marchese, P. Pezzoli, S. Griffin, E. Buxton, and V. Boyer. 1994. Quantitative PCR: An overview. In The polymerase chain reaction (ed. K.B. Mullis, F. Ferré, and R.A. Gibbs), pp. 67-88. Birkhauser, Boston, MA.

7. Raeymaekers, L. 1993. Quantitative PCR: theoretical considerations with practical implications. Anal. Biochem. 214: 582585.

8. Huber, C.G., P.J. Oefner, and G.K. Bonn. 1995. Rapid and accurate sizing of DNA fragments on alkylated nonporous poly(styrene-divinylbenzene) particles. Anal. Chem. 67: 578-585.

9. Oefner, P.J., C.G. Huber, E. Puchhammer-Stockl, F. Umlauft, K. Grunewald, G.K. Bonn, and C. Kunz. 1994. High-performance liquid chromatography for routine analysis of hepatitis C virus cDNA/ PCR products. BioTechniques 16: 898908.

10. Huber, C.G., P.J. Oefner, and G.K. Bonn. 1993. High-resolution liquid chromatography of oligonucleotides on nonporous alkylated styrene-divinylbenzene copolymers. Anal. Biochem. 212: 351-358.

11. Gilliland, G., S. Perrin, K. Blanchard, and H.F. Bunn. 1990. Analysis of cytokine mRNA and DNA: detection and quantitation by competitive polymerase chain reaction. Proc. Natl. Acad. Sci. 87: 27252729.

12. Ferré, F. 1992. Quantitative or semiquantitative PCR: Reality versus myth. PCR Methods Applic. 2: 1-9.

13. Zhou, J. and E.P. Hoffman. 1994. Pathophysiology of sodium channelopathies: Studies of sodium channel expression by quantitative multiplex fluorescence polymerase chain reaction. J. Biol. Chem. 269: 18563-18571.

14. Zhou, J., S.J. Spier, J. Beach, and E.P. Hoffman. 1994. Pathophysiology of sodium channelopathies: Correlation of normal/ mutant mRNA ratios with clinical phenotype in dominantly inherited periodic paralysis. Hum. Mol. Genet. 3: 1599-1603.

15. De Kant, E., C. Rochlitz, and R. HerImann. 1994. Gene expression analysis by a competitive and differential PCR with antisense competitors. BioTechniques 17: 934-942.

16. Porcher, C., M.C. Malinge, C. Picat, and B. Grandchamp. 1992. A simplified method for determination of specific DNA or RNA copy number using quantitative PCR and an automatic DNA sequencer. BioTechniques 13: 106-114.

17. Ilkonen, E., T. Manninen, L. Peltonen, and A.C. Syvanen. 1992. Quantitative determination of rare mRNA species by PCR and solid-phase minisequencing. $P C R$ Methods Applic. 1: 234-240.

18. Yang, B., R. Yolken, and R. Viscidi. 1993. Quantitative polymerase chain reaction by monitoring enzymatic activity of DNA polymerase. Anal. Biochem. 208: 110116.

19. van Gemen, B., P. v.d Wiel, R. van Beuningen, P. Sillikens, S. Jurrlaans, C. Dries, R. Schoones, and T. Klevits. 1995. The one-tube quantitative HIV-1 RNA NASBA: Precision, accuracy and application. PCR Methods. Applic. 4: S177-S184.

Received August 30, 1995; accepted in revised form November 6, 1995. 


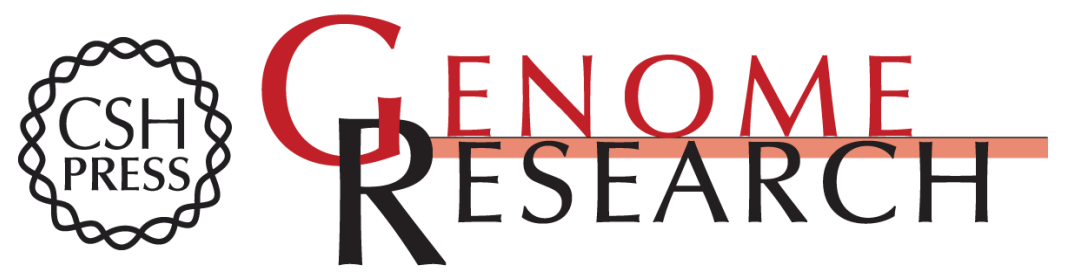

\section{Accurate and absolute quantitative measurement of gene expression by single-tube RT-PCR and HPLC.}

A Hayward-Lester, P J Oefner, S Sabatini, et al.

Genome Res. 1995 5: 494-499

Access the most recent version at doi:10.1101/gr.5.5.494

References This article cites 17 articles, 3 of which can be accessed free at:

http://genome.cshlp.org/content/5/5/494.full.html\#ref-list-1

\section{License}

Email Alerting Receive free email alerts when new articles cite this article - sign up in the box at the Service top right corner of the article or click here.

\section{Affordable, Accurate Sequencing.}

To subscribe to Genome Research go to:

https://genome.cshlp.org/subscriptions 